\title{
Does Teaching English in Saudi Primary Schools Affect Students' Academic Achievement in Arabic Subjects?
}

\author{
Othman Aljohani \\ English Language Centre, Institute of Public Administration \\ Jeddah, Saudi Arabia \\ E-mail: johanio@ipa.edu.sa
}

Doi:10.7575/aiac.alls.v.7n.1p.214

Received: 03/10/2015

URL: http://dx.doi.org/10.7575/aiac.alls.v.7n.1p.214

Accepted: 18/12/2015

\begin{abstract}
The global trend of introducing second language learning, namely, English, in primary schools is increasing. In Saudi Arabia, where English has never been taught in primary schools, the government to implement English as a second language at the primary level in 2005; however, this generated controversy. Opposition to the learning of English has been based on religious, cultural, and educational arguments. The latter argument consists of claims that learning English at a young age might influence children's mother tongue development and influence their academic success. This paper investigates the impact of teaching English in Saudi primary schools on students' achievement in Arabiclanguage subjects. This quantitative research aims to inform the debate on second language learning in primary schools by studying children's examination results in the Arabic subject areas of grammar, reading, and writing. The sample consisted of primary school students from years 1 to 6 as well as year 6 students from the last year before (2004) and the first year after (2005) the introduction of English. Student results from four primary schools (two government schools and two private schools) were collected and analysed. This study found no indication of a positive or negative impact of learning English on students' achievement in Arabic subjects. However, private school students who studied English beginning in their first year of school had better results in the Arabic subjects that were the focus of this research.
\end{abstract}

Keywords: second language acquisition, language impact, ESL

\section{Introduction}

There is a global trend of encouraging learning foreign languages in school. In many parts of the world, students learn one or two languages in addition to their first language as compulsory subjects beginning early in their schooling. This is now the case in Saudi Arabia, where English has been implemented in all primary schools beginning in year 1. However, these developments in Saudi Arabia have generated a great deal of controversy.

In Saudi Arabia, some people oppose the idea of teaching children other languages, arguing that languages represent cultures and that they are afraid of their impact on Saudi tradition and culture (Al-Ahmari, 1992; Al-Naser, 1991; AlShammary, 1989). Others oppose language learning for religious reasons, as Arabic is the language of the Quran and some languages represent different religions and religious values (Al-Shammary, 1989). However, the main point in this debate is the impact of foreign languages on the first language acquisition process.

Most of those who are opposed to the idea of teaching other languages to young children believe that it might affect their proficiency in their first language and might prevent them from developing it properly (Al-Thaferi, 1999; AlShammary, 1989). They claim that languages should not be taught to young learners until they are adults and fully proficient in their first language to prevent such an effect. They believe that the priority at this age should be the acquisition of the first language, which might be disturbed by the second language learning process. These arguments are contrary to the idea of the critical period hypothesis, which claims that childhood is the best age to begin learning other languages and that younger students learn better than older ones (Long, 1990; Johnson \& Newport, 1989; Patkowsky, 1980; Penfield \& Roberts, 1959; Lenneberg, 1967).

This paper aims to contribute to this discussion by exploring whether the introduction of the English language at the primary level has any impact on students' academic achievements in their first-language subjects (grammar, reading, and writing). Such an exploration is motivated by opponents' of this movement claim that introducing English into the curriculum early in primary school will have an adverse impact on students. This study seeks to make an initial investigation of this claim and see whether it may or may not be supported by empirical data.

This paper will present a background to the research by discussing policies related to learning English as a second language (ESL) in Saudi primary schools, comment on the history of second language learning in Saudi schools and provide details of the debate surrounding the policies. The literature on the theories and practice of second language learning in the primary years is presented and the research is described. The paper concludes with a discussion of the research's findings and implications. 


\section{Background}

\subsection{English in Saudi schools}

Before the commencement of the plan to teach English at the primary level in government schools in 2005, English was only taught in Saudi government schools as a foreign language subject beginning at the intermediate level (year 7). It was taught in four 45-minute periods per week in classes of 30 to 40 students who only spoke Arabic. Moreover, all of the English teachers were Saudis or from other Arabic-speaking countries.

In private schools, on the other hand, English is taught from the first year of school and even before that if the school has a kindergarten level. Unlike in government schools, class sizes do not exceed 25, and sometimes, there are several students who speak languages other than Arabic. The duration of teaching periods is the same as in government schools, but English is taught five times per week. Moreover, private schools usually have better learning facilities, such as language labs and audio-visual aids, which help students to learn more effectively. However, English in private primary schools is taught as an elective subject that is not counted in students' overall average grade of the year.

In 2005, the Ministry of Education embarked on a six-year plan to implement English at the primary level in government schools (years 1 to 6) by introducing English in year 6 in the first year. However, the plan was stopped after the first year for a number of reasons, such as an insufficient number of English teachers and schools that were not ready for the program. After revision, the plan was resumed in 2011, and the ministry decided to teach English only in the last three years of the primary level (years 4 to 6).

\subsection{The debate of English-teaching age in Saudi Arabia}

There is a strong debate in the educational community in Saudi Arabia about the benefits of introducing English at the primary level. Many people believe in the importance of English as an international language, and they believe that learning English should start from the first year of school, when students are at an appropriate age to acquire other languages (Al-Jarf, 2004). Others argue that teaching English, or any other language, at this early age may negatively affect the students' proficiency in their first language (Husain, 2002; Al-Ghanim, 2000; Al-Ahmari, 1992; Al-Naser, 1991; Al-Shammary, 1989).

The remarkable point in this debate is that both parties tend not to provide any evidence for their arguments. Those who are in favour of teaching English at the primary level do not talk about the reasons why students who graduate from secondary schools have weak levels of English after they have studied it for six years (Jazaeri, Asharq Alawsat Newspaper). They merely talk about giving the students more time in the learning process, as if they are quite sure that this is a problem of time without presenting any evidence to support this view. In fact, studies on the low achievement of Saudi learners in learning English blame the way English is taught and the amount of weekly hours that are devoted to English tuition (Al-Jarf, 2004; Al-Shammary, 1989).

On the other hand, opponents of the idea of teaching English in primary schools do not base their arguments on empirical studies that show the impact on the Arabic language of primary-level children learning English (Husain, 2002; Al-Ghanim, 2000; Al-Ahmari, 1992; Al-Naser, 1991; Al-Shammary, 1989). Rather, they tend to couch their argument in terms of how Western values, supposedly represented by the English language, could affect students at this young age. Moreover, when they talk about the impact of the English language on students' proficiency in Arabic, they do not differentiate between the process of learning other languages and the process of language acquisition. They also talk about English taught in schools as if it were a complete immersion program rather than being a stand-alone subject that students study for 45 minutes four times per week in a completely Arabic society inside and outside of school.

\section{Literature Review}

In this literature review, research on second language learning, the benefits and disadvantages of learning a second language when young, and cultural and religious issues of learning English in primary schools in Saudi Arabia are discussed; further, their relation to this research is explained.

There is no doubt that learning other languages has an impact on learners. Learners of other languages are believed to be different from monolingual learners. Meara (1983) argued that a person who speaks two languages does not behave in the same way as a person who speaks just one of those languages. This means that even if the learner's first language was not influenced by learning a second language, there should be an impact on his or first language or on the way he or uses it, whether this is negative or positive.

A government study in Qatar (cited in Al-Mutawa, 1996) conducted by the Ministry of Education to measure the lingual development of Arabic in young learners and how it might be affected by learning other languages showed that students who never studied English had better Arabic comprehension and speaking skills. However, all of the participants scored the same in Arabic achievement in the last year of the study. In 1986, Ashor (cited in Al-Mutawa, 1996) conducted a similar study on year 4 and year 6 students who had studied English in kindergarten for two years before school age in Egypt and found that their academic achievement in their first language was slower compared to those students who did not learn a second language; however, the negative impact disappeared as the students got older. The findings of the above two studies support the idea that any negative impact can be made up in later stages as students progress in their first language.

Al-Thaferi (1999) conducted a study to investigate the impact of introducing English at the primary level in Kuwaiti schools on the students' academic achievements, attitude, and language interference on all language skills. He found that students who had not studied English achieved better grades in Arabic subjects. The study also showed that interference between English and Arabic did exist from English to Arabic in all language skills.

In Saudi Arabia, Al-Jarf (2004) surveyed 40 students who were studying in international schools that use English as the teaching language and found that English was the dominant language for all of the students in the sample, especially in reading and writing. Moreover, she found that 35\% preferred to communicate in English, while $25 \%$ used some English 
words when they spoke in Arabic. She also found that $40 \%$ could not speak classical Arabic, $35 \%$ could not read or write in Arabic, and $65 \%$ had difficulty reading and writing and faced spelling problems when writing in Arabic. They also had trouble expressing their ideas in Arabic and understanding the meaning of words in written text. Finally, 10\% of the students in the sample enrolled in King Saud University and faced many problems with the university's Arabic core courses and with other subjects taught in Arabic.

In contrast, there is considerable literature about the positive impact of learning other languages on the first languagelearning process. Many studies argue that those who learn other languages, especially at an early age, have better opportunities to know and learn their first language. Goethe (cited in Vygotsky, 1962) said "he who knows no foreign language does not truly know his own." Some of these studies talk about the benefits of learning other languages on the learners' metalinguistic awareness development that helps them not only in their first language acquisition but also in learning any other languages in general.

Kecskes and Papp (2000) reported that there are many studies (Grandell, 1993, 1995; Holmstrand, 1979; Kecskes \& Papp, 1995; Papp, 1991) suggesting that higher metalinguistic awareness helps learners to develop a more conscious and sophisticated use of their first language system. They also reported that linguists believe that the only important impact of foreign language that is taught in classrooms is on developing students' metalinguistic awareness. They claimed that not only bilingual learners but also learners of a foreign language in regular classrooms could have enhanced first language development. As students in schools tend to pay more attention to vocabulary development and sentence structure when they learn a foreign language, they usually achieve better results in their first language grammar tests.

Clyne (1986) claimed that children who learn a second language earlier have a better chance of developing metalinguistic awareness and can understand and think about their first language functions better than others. Moreover, he said that this early metalinguistic awareness seems to support their reading skills. He claimed that learners of other languages are usually better than monolingual children in differentiating between form and content. Furthermore, the two linguistic systems have helped them to develop verbal flexibility and better divergent thinking. Clyne claimed that teaching second languages in schools should be considered as a way to develop children's potential.

Diaz and Klingler (1987) (cited in Noh, 2001) said that learners who have the opportunity to learn two or more languages at an early age are more likely to develop a greater metalinguistic awareness and exhibit better performance on verbal and non-verbal tasks. Bamford and Mizokawa (1991) (cited in Noh, 2001) argued that this could help the learners to develop their cognitive system. According to Lambart, Genesee, Holobow, and Chartrand (1993) (cited in Noh, 2001), immersion programs have helped students to improve their speaking and writing skills in their first language. Masciantonio (1977) surveyed U.S. research on the effects of Latin instruction and found that learning Latin helped students from all backgrounds in developing their vocabulary and reading skills.

Finally, several studies denied any impact of learning other languages on students' first language. Cummins (1993) (cited in Noh, 2001) argued that students who received bilingual education developed in the first language and had the same academic achievement as those who studied in monolingual programs. According to Kecskes and Papp (2000), the following studies (cf. Burstall, 1970; Burstall, Jamieson, Cohen, \& Hargeaves, 1974; Smith, 1967), which focus on children under the age of 12, found that there was no impact of foreign languages on the first language. In 1995, Rodriguez, Diaz, Duran, and Espinosa studied 50 children between the ages of 3 and 5 whose mother tongue was Spanish. They found that those who had been enrolled in programs that taught both English and Spanish were better in the second language while maintaining the same proficiency in the first language as other children who only studied the first language. Some studies (Bjorklund, 1995; Grandell, 1993, 1995; Hoglund, 1992; West, 1993) (cited in Kecskes \& Papp, 2000) that tested the Finnish skills of students who studied in a Swedish immersion program in Finland compared students' skills in their first language with the same skills of the monolingual Finnish students and found that there was no significant impact of foreign language on the first language and the students' academic achievement.

Bregy, Brohy, and Fuchs (2000) studied French-speaking students' results at the end of year 2 in Swiss schools (these students had started learning German between the ages of 4 and 5). They found that there was no evidence of the impact of learning a second language at this age on the first language or on the students' academic achievement. A study from a similar context to that of this paper supported these findings. In Kuwait, Eassa and Al-Mutawa (1998) conducted a study to investigate the impact of introducing English on students' academic achievements in Arabic in year 2 in Kuwaiti schools. They studied the students' results in Arabic before and after the introduction of English. The study showed that learning English in year 2 did not affect the process of first language (Arabic) acquisition.

\section{Methodology}

\subsection{Theoretical perspective}

The view of language adopted in this paper is a Vygotskyan one (Vygotsky, 1962): language is viewed as a cultural tool. Children in primary school have a sophisticated understanding of language and culture and will use it in a variety of modes to externalise mental processes and develop shared understandings within a context and with a particular social group. Middle childhood is characterised by an ability to use higher-order language, problem solve, think logically, and persist at tasks. Further, the company of peers becomes increasingly important and influential at this age. This study focused on two boys' schools and two girls' schools (for a total of four schools), where children's knowledge of the Arabic language and culture is supported by their formal use of symbolic systems, which allows them to explicate and elaborate ideas. Second language learning will be impacted by the degree of exposure to the language and the differences between the languages, in this case, Arabic and English. 


\subsection{Aims}

There are many ways in which language B (second language) may affect language A (first language). In this paper, where the main focus is on academic achievement in the students' first language, the investigation will be centred on the students' results in Arabic-language subjects at school. Therefore, this paper aims to investigate the impact of teaching English in Saudi primary schools on the students' achievements in Arabic subjects (grammar, reading, and writing) by comparing their results in these Arabic subjects before and after the introduction of English in primary school.

This part of the study involves gathering empirical data on students' achievements in Arabic subjects in the school curriculum and analysing it in order to see if there are significant changes in the students' achievements in Arabic subjects (grammar, reading, and writing) that might correlate to the introduction of English. The study intends to look for marked patterns in groups of learners to see if the times and schools in which English is introduced have any effect on students' average scores in Arabic subjects.

The data is expected to give a clear indication of whether achievement in Arabic learning in the curriculum is affected by the introduction of English in primary school. In this investigation, exam results in Arabic-language subjects will form the data sets, and a comparison of means between groups in the sample will be used to identify overall trends and patterns.

4.3 Research questions

The main aim of this paper is to answer the following research questions:

1) Does teaching English in Saudi primary schools affect the students' academic achievements in Arabiclanguage subjects (grammar, reading, and writing)?

2) If there is an effect on the students' academic achievements in Arabic-language subjects (grammar, reading, and writing), is it positive or negative?

3) How long does it take for any effect to become apparent?

4) If there is an impact only in the later years, is this a result of learning English or of other factors?

The answers to these questions will contribute evidence-based data to inform the debate in Saudi Arabia on the impact of the early introduction of English on students' academic achievements in these Arabic subjects.

4.4 Participants

The study sample consists of 2,000 students from four primary schools (male and female government and private schools) in Jeddah, Saudi Arabia. The students' results in Arabic subjects were followed from year 1 to year 6 and were evaluated at the end of each year. The paper sample covers the students from year 1 to year 6 and the students in year 6 from the last year before introducing English (2004) and the first year after introducing English (2005).

4.5 Data

The data used in this paper was taken from the records of the students' final grades in their school subjects in Arabic and English. These records were obtained directly from the sample schools with the permission of the Education Department of Jeddah. They consist of the students' midterm and final tests (60\%), quizzes (30\%), and homework and in-class participation (10\%) (for a final grade out of $100 \%$ ).

4.6 Analysis

Since this study focuses on analysing students' results in a descriptive way to find the effects of introducing English, if there are any, on the students' performance in Arabic subjects (grammar, reading, and writing), this will be a quantitative study that mainly analyses the students' final results in all of the intended subjects and compares them against each other to find out if there are any indications of effect.

Students' results in English and Arabic grammar, reading, and writing were put in a list form that contained the year, the subject title, the students' level, and their final grade out of 100. The students' results were classified in spread sheets according to school type, gender, study level, year, and subject. The grade average for each subject and level, and the overall average for all of the subjects, were calculated. However, only the students' overall averages in all of the Arabic subjects were used, since they reflect the achievement of the students' Arabic language skills in general. Consequently, the students' results were analysed collectively by using their overall achievement averages in all subjects.

In order be more specific, the following nil hypothesis was created to provide a focus for the examination of the data collected:

\section{- Teaching English in Saudi primary schools has no impact on students' academic achievement in Arabic} subjects.

The results of the study were analysed in three stages, as follows:

a. Same levels in different school systems

Students' results in Arabic subjects (grammar, reading, and writing) for years 1 to 6 from private schools (where English is taught) and government schools (where English is not taught) were compared to determine the patterns of achievement in each school system. Then, those patterns were analysed for differences. If different patterns were found, each of them was observed to see if learning English affected the students' achievement in Arabic subjects positively or negatively.

b. Different levels in the same school system

Students' results in Arabic subjects for year 6 in government schools in 2005 (when English is taught) were compared with their results in Arabic subjects from the previous years (when English was not taught) to see if they maintained their progression pattern in Arabic after they started learning English. Moreover, private school students' (who study English in all years) results were used as a control group in this stage of the analysis. 
c. Same level in the same school system

Students' results in Arabic subjects for year 6 in 2005, the first year of the introduction of the English language as a school subject, were compared with the students' results in Arabic subjects for year 6 in 2004, the last year before introducing English as a subject, to see if there were any indications of change in the students' achievement in Arabic subjects.

\section{Results}

5.1 Student averages in Arabic subjects from year 1 to year 6 (1997-2002)

Between 1997 and 2002, English was not taught in government schools, whereas private school students learned English in all years of primary school starting in year 1. In this section, students' average scores for their Arabic subjects are presented year by year in order to investigate what patterns exist across the school sectors, and since different school sectors introduced English at different times, to see if there is any significant change in the scores in Arabic subjects as well as how they might have been affected by the introduction of English. The analysis covers each year individually to examine the paper's hypothesis that learning English has no impact on student achievement in Arabic subjects.

These average scores are presented in Figures 1 to 6 and are organised by school type. Schools in Saudi Arabia are all single-sex, and there are two school sectors: government schools and independent private schools. There are therefore four types of schools.

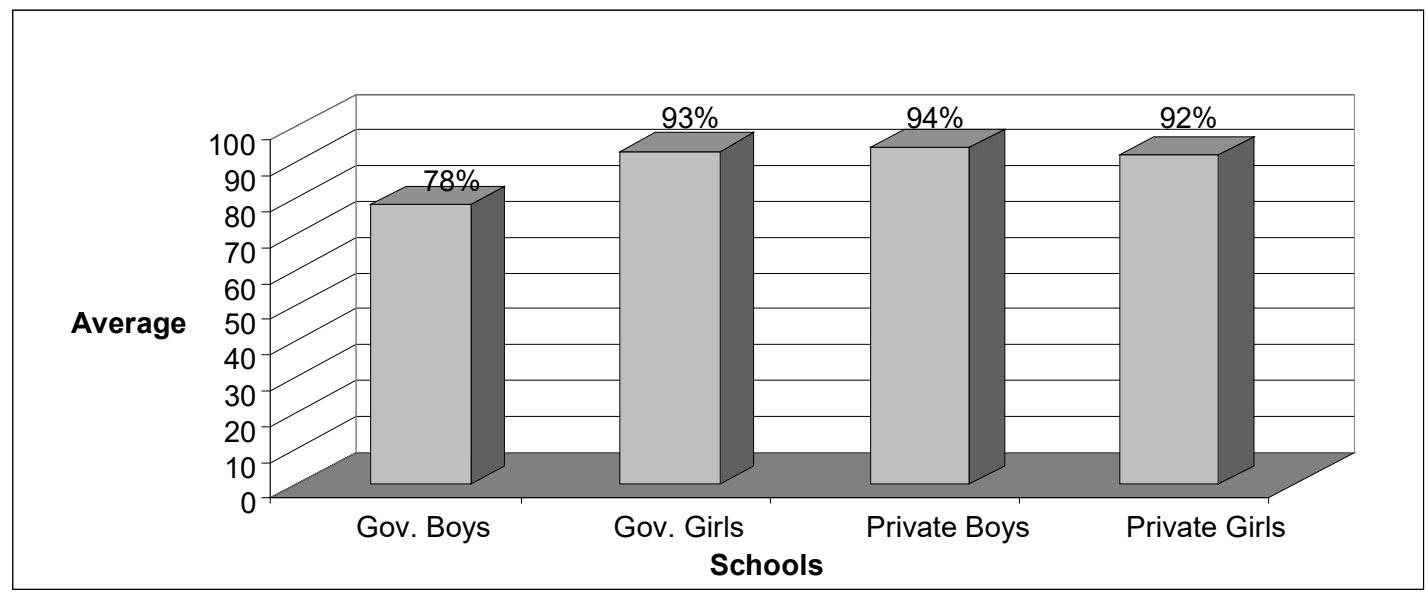

Figure 1. Students' averages in year 1 (1997)

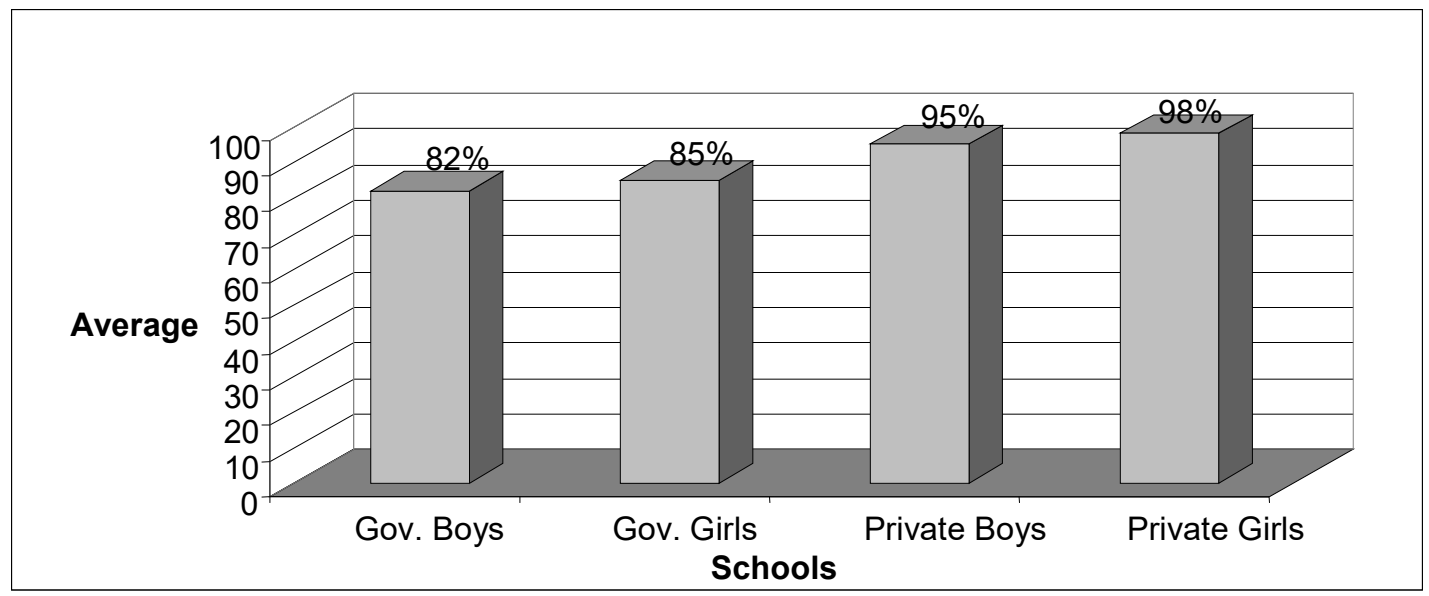

Figure 2. Students' averages in year 2 (1998) 


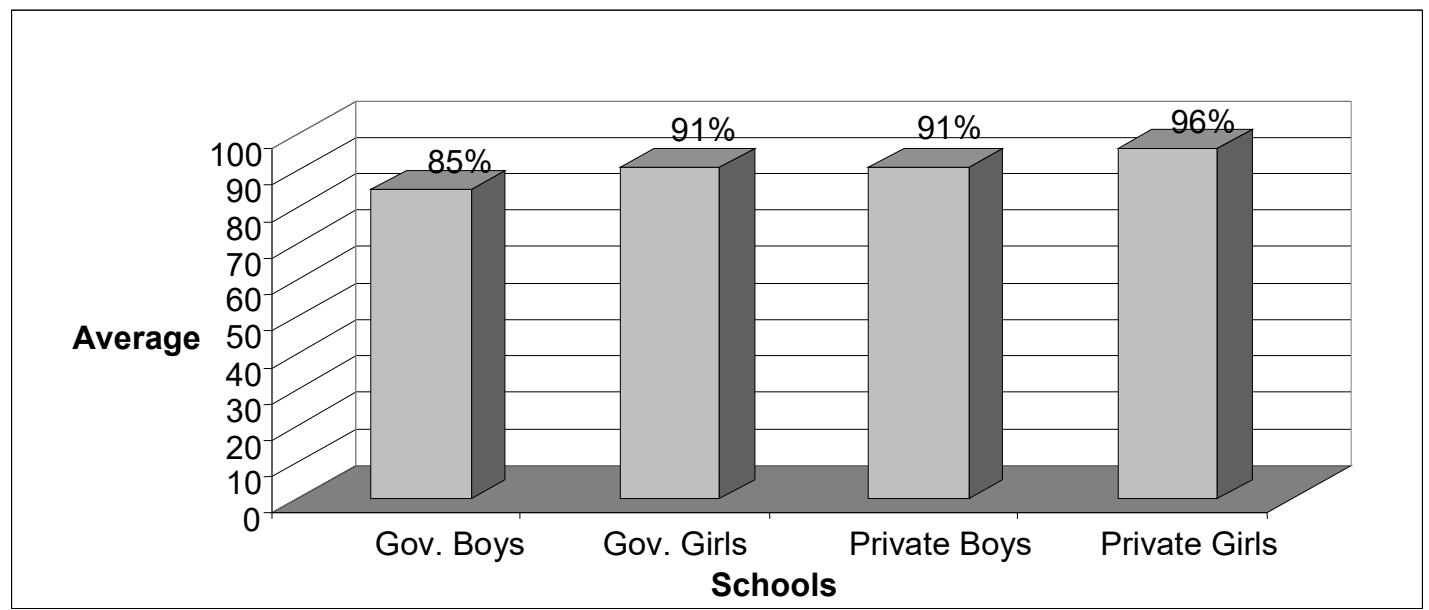

Figure 3. Students' averages in year 3 (1999)

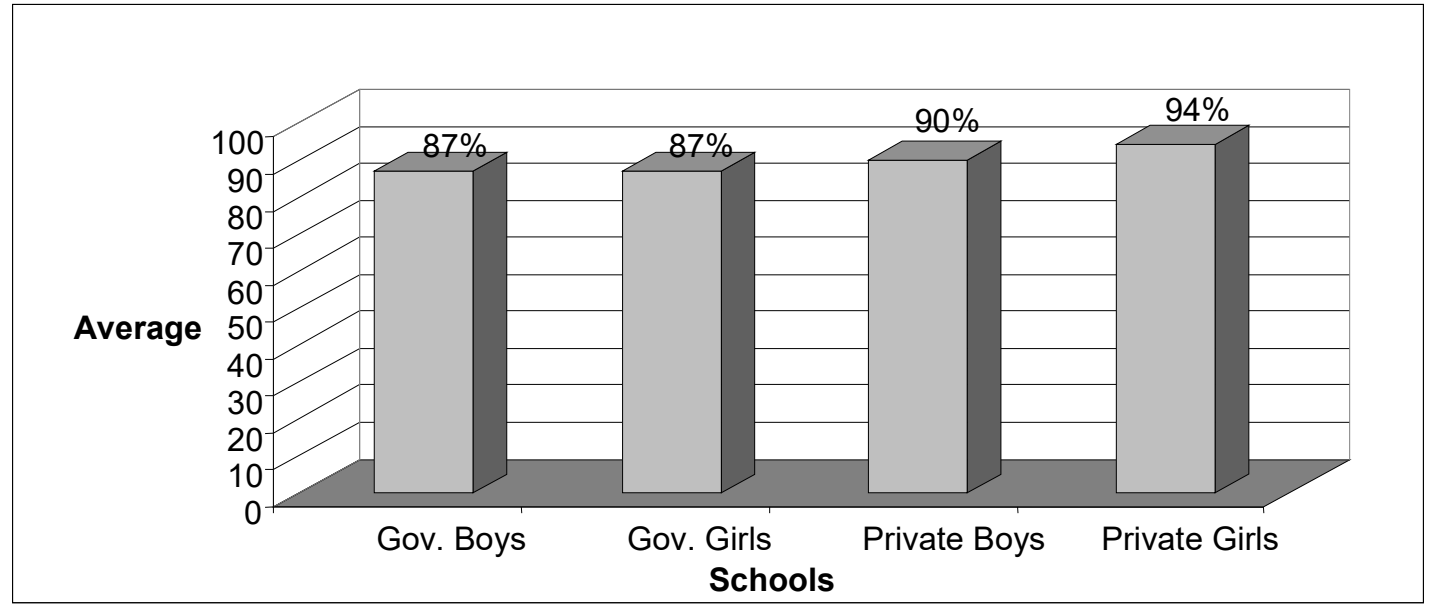

Figure 4. Students' averages in year 4 (2000)

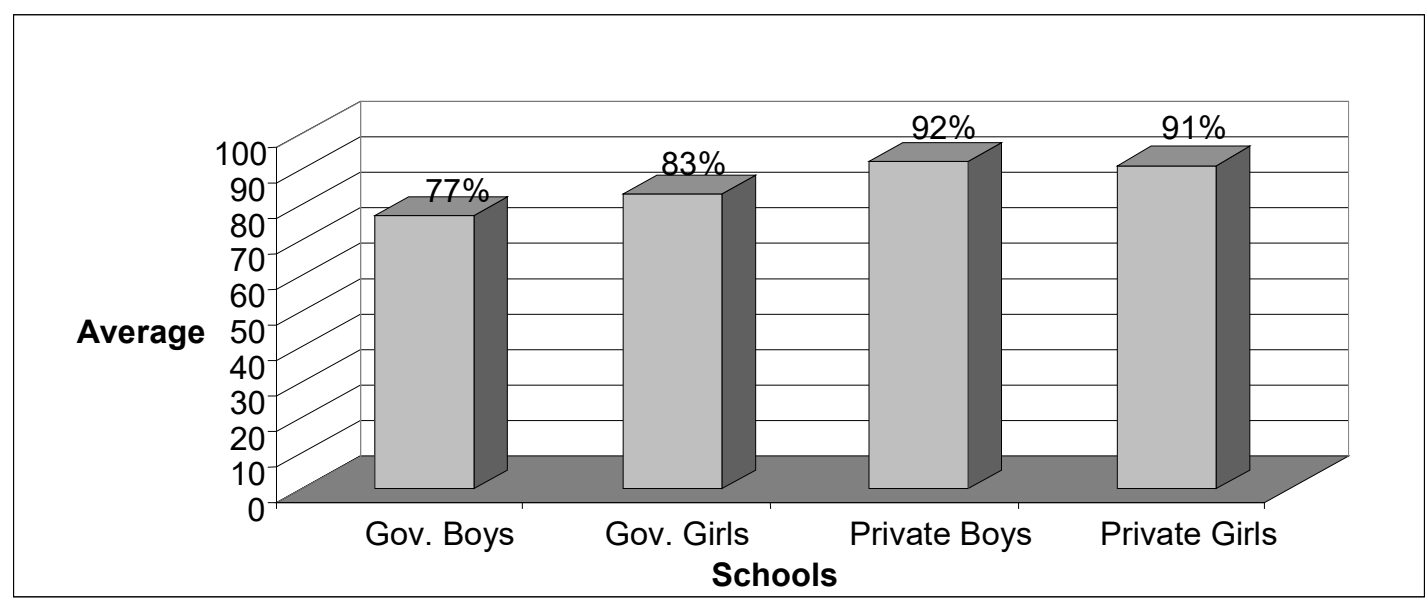

Figure 5. Students' averages in year 5 (2001) 


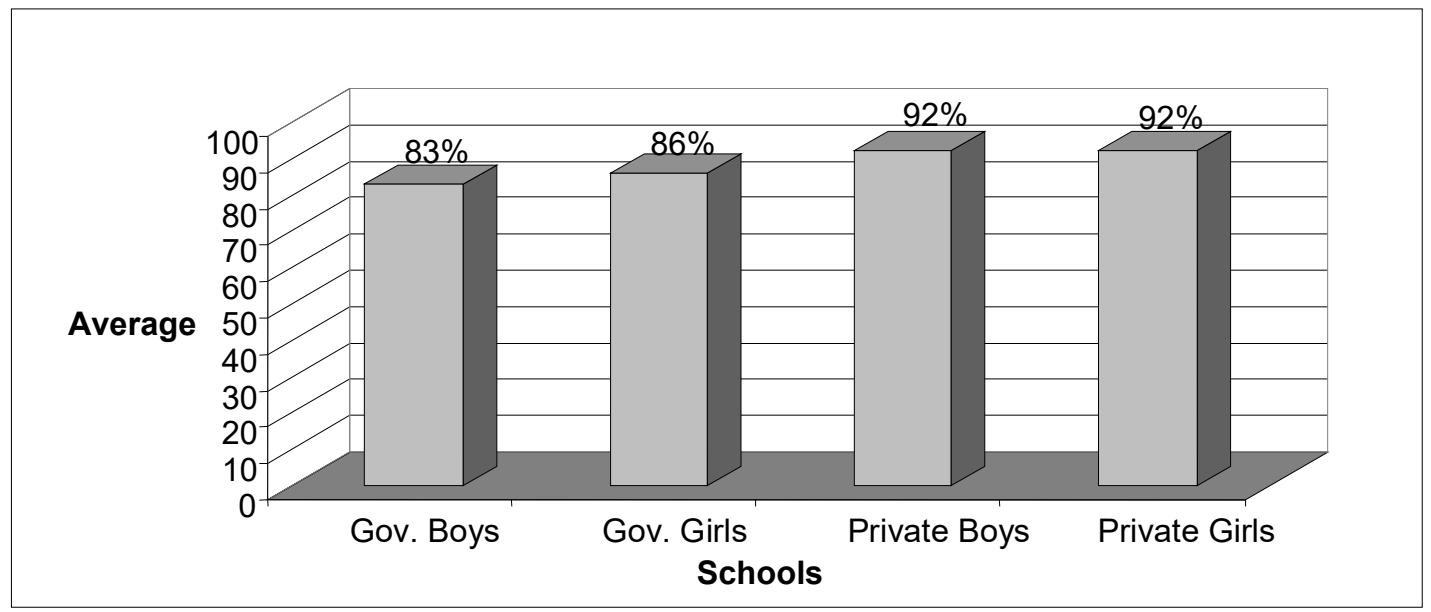

Figure 6. Students' averages in year 6 (2002)

Table 1 depicts the students' average scores for all Arabic subjects by school type and gender for each year, with the averages presented in percentages.

Table 1. Comparison of Students' Averages in Arabic Subjects (1997-2002)

\begin{tabular}{cccccc}
\hline \multirow{2}{*}{ Level } & \multicolumn{2}{c}{ Gov. Schools } & \multicolumn{2}{c}{ Private Schools } & \multirow{2}{*}{ Cohort Size* } \\
\cline { 2 - 4 } & Boys & Girls & Boys & Girls & \\
\hline Year 1 (1997) & $78 \%$ & $93 \%$ & $94 \%$ & $92 \%$ & $34-100$ \\
\hline Year 2 (1998) & $82 \%$ & $85 \%$ & $95 \%$ & $98 \%$ & $33-100$ \\
\hline Year 3 (1999) & $85 \%$ & $91 \%$ & $91 \%$ & $96 \%$ & $29-100$ \\
\hline Year 4 (2000) & $87 \%$ & $87 \%$ & $90 \%$ & $94 \%$ & $26-100$ \\
\hline Year 5 (2001) & $77 \%$ & $83 \%$ & $92 \%$ & $91 \%$ & $19-100$ \\
\hline Year 6 (2002) & $83 \%$ & $86 \%$ & $92 \%$ & $92 \%$ & $42-90$ \\
\hline
\end{tabular}

Note. *Different cohort sizes existed in different schools. The range is presented.

These figures show a consistent pattern of performance in which the private school students generally obtain higher averages than their government school peers, with the boys in government schools having lower scores in Arabic in the early years. The differences are not significant, except in the early years, where the boys in government schools have an average that is several percentage points below that of their peers. One trend that can be discerned is that the greatest differences in the averages in most years are between boys in government schools (at the lower end) and girls in private schools (at the upper end).

As English was taught in the private schools at all of these year levels and not taught until year 6 in the government schools, there is no pattern of results that seems to be affected by learning English, as the changes in the averages do not clearly coincide with the introduction of English in the respective school sectors. The differences that are evident seem to reflect gender and school type, with private schools getting better results, particularly for boys, in most years. Thus, the strongest claim that can be made from this data in relation to learning English is that the early introduction of English in private schools improves scores in Arabic-language subjects for boys. However, such a claim would be difficult to sustain, as there may be other factors that influence these differences between the sectors.

\subsection{Averages by student group}

If the same data is examined in a different way, by looking at the averages by student group year by year, any change attributable to the introduction of English may be more evident. If the introduction of English had an effect, it may show up as a change in the years in which it is introduced. This would create a pattern of difference between the firstyear results and the later-year results in the private schools as well as a difference in the year 6 results for the government schools. Figures 7 to 10 show the annual averages for each of the four groups. 


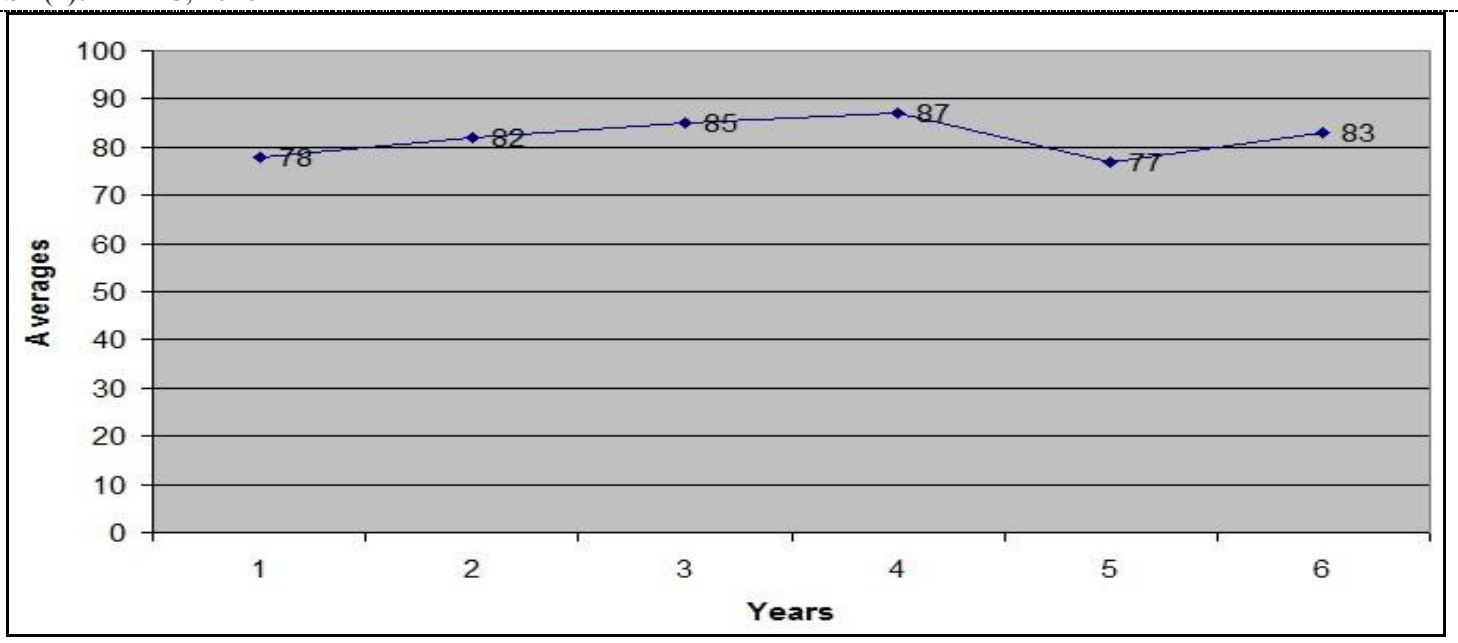

Figure 1. Progression patterns for government school boys

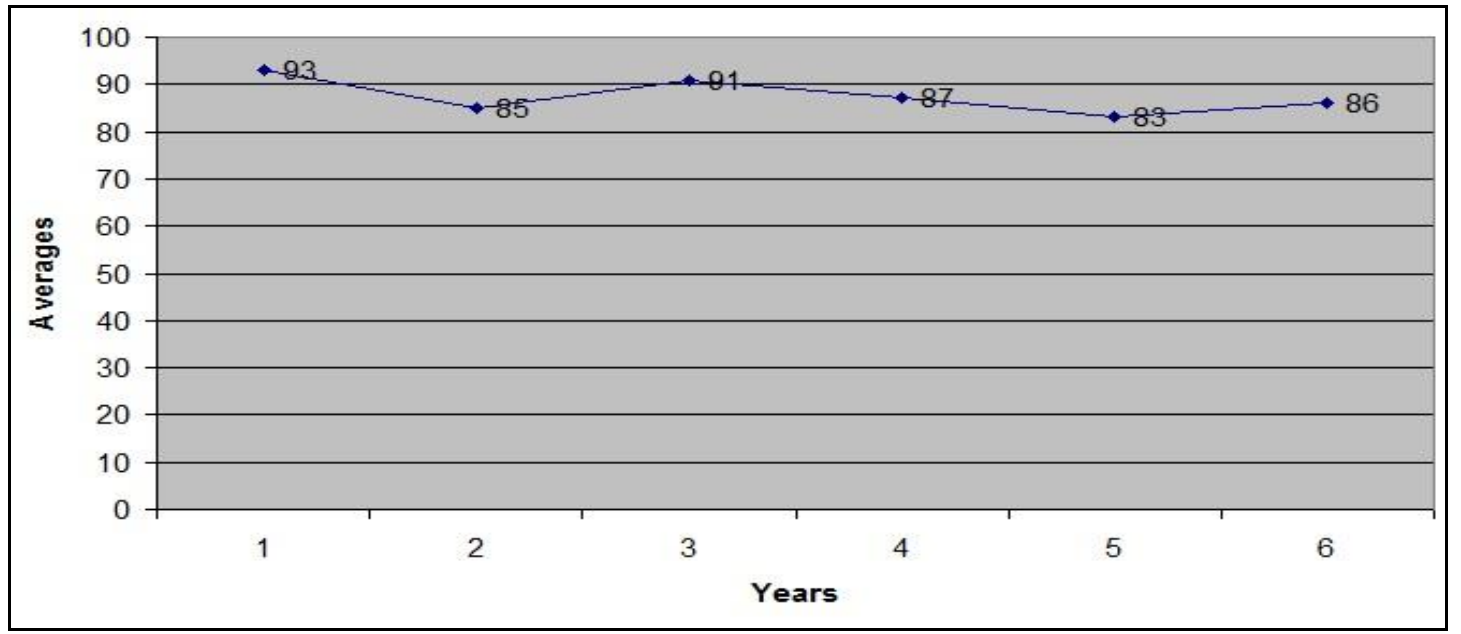

Figure 2. Progression patterns for government school girls

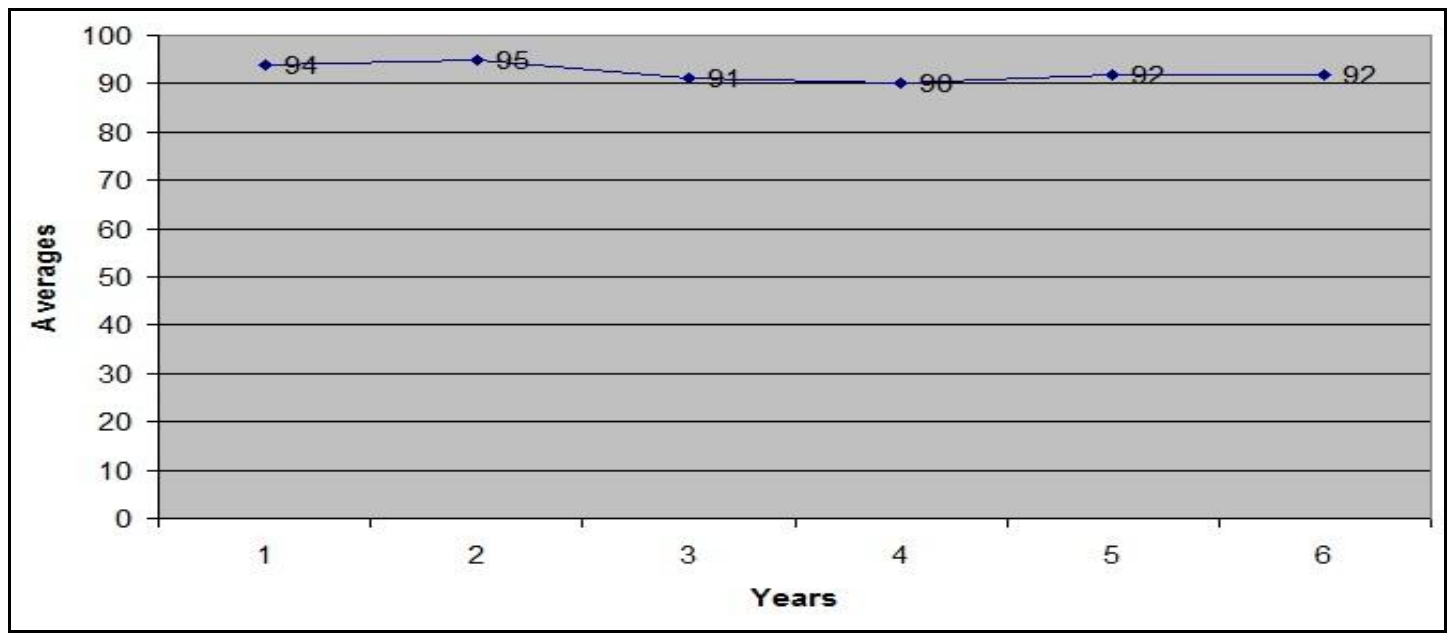

Figure 3. Progression patterns for private school boys 


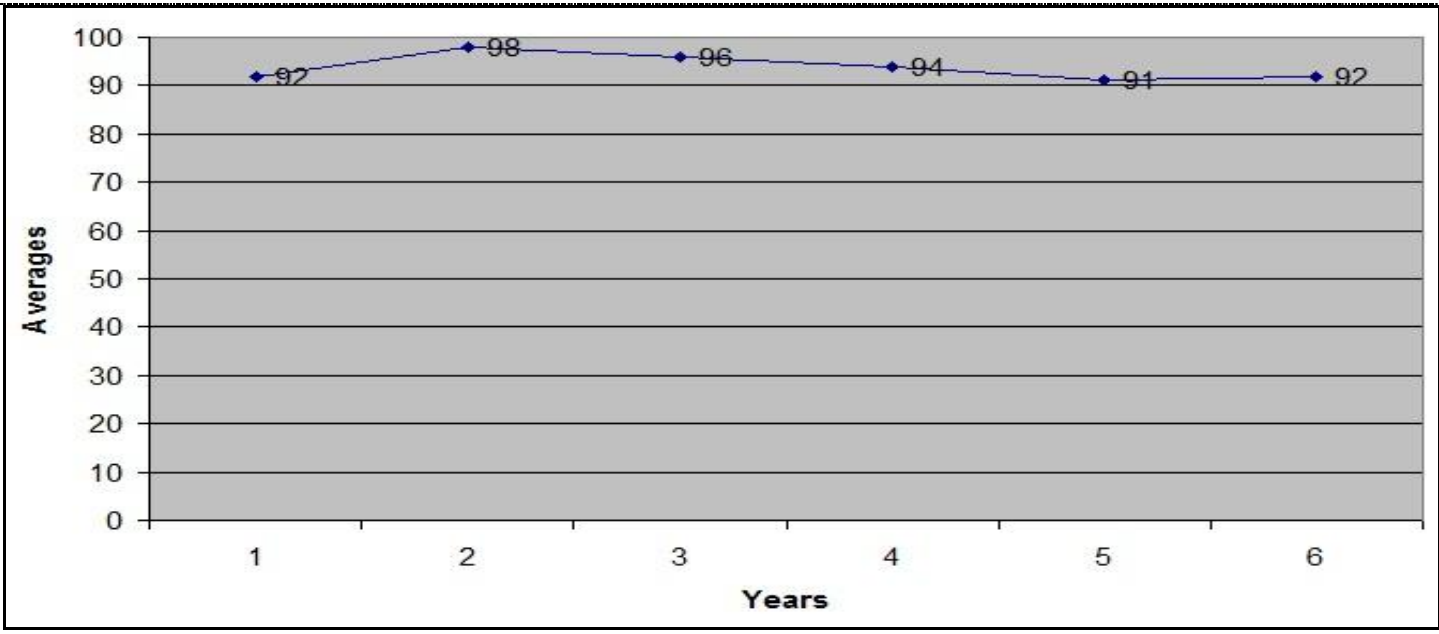

Figure 4. Progression patterns for private school girls

While there are some small variations that might fit this pattern, there was no consistent pattern that reflected the introduction of English. Figures 7 to 10 show that the private school girls' results are significantly lower in year 1 than in year 2, but this pattern is not replicated in the private school boys' results. If the lower results for the private school girls are the result of teaching English in year 1, this has disappeared by year 2, when this group has the highest of any average in the whole data set. In the government sector, both the boys' and girls' averages rise slightly in year 6 from year 5; in both cases, year 5 has the lowest average results. This could result in a claim that the introduction of English in government schools is associated with a slight increase in Arabic language scores, but as these changes may also be seen as part of a pattern that involves some variations in years, it may be difficult to sustain a claim that these changes are attributable to the introduction of English.

\subsection{Government school students' averages in Arabic before and after the introduction of English}

This section describes data related to students of the same schools in year 6 in 2004 and 2005, the years before and after the introduction of English as a subject in government schools. The averages of the students in government schools in all Arabic subjects in 2004, before learning English, was compared with their averages in 2005, after the introduction of English, to see if there was any variation in their achievement. The students' averages in Arabic in 2002 that were used in previous sections were used in this comparison to give more validity to the results. The averages of the private school students were used in this stage as a control group to see if the variation in the averages of the government school students (if there is any) happened because of the introduction of English or because of other factors. If the variation (if there is any) was accrued in both types of school, then the reason will be attributed to factors other than learning English.

Table 2. Students' Averages in Arabic-Language Subjects Before and After Learning English

\begin{tabular}{|c|c|c|c|c|c|}
\hline \multirow[t]{2}{*}{ Level } & \multicolumn{2}{|c|}{$\begin{array}{l}\text { Government Schools } \\
\text { (English Only in 2005) }\end{array}$} & \multicolumn{2}{|c|}{$\begin{array}{c}\text { Private Schools } \\
\text { (English in All Years) }\end{array}$} & \multirow[t]{2}{*}{ Cohort Size* } \\
\hline & Boys & Girls & Boys & Girls & \\
\hline Year $6(2002)$ & $83 \%$ & $86 \%$ & $92 \%$ & $92 \%$ & $42-90$ \\
\hline Year 6 (2004) & $84 \%$ & $89 \%$ & $91 \%$ & $95 \%$ & $16-100$ \\
\hline Year $6(2005)$ & $82 \%$ & $89 \%$ & $92 \%$ & $95 \%$ & $23-100$ \\
\hline
\end{tabular}

Note. *Different cohort sizes existed in different schools. The range is presented. 


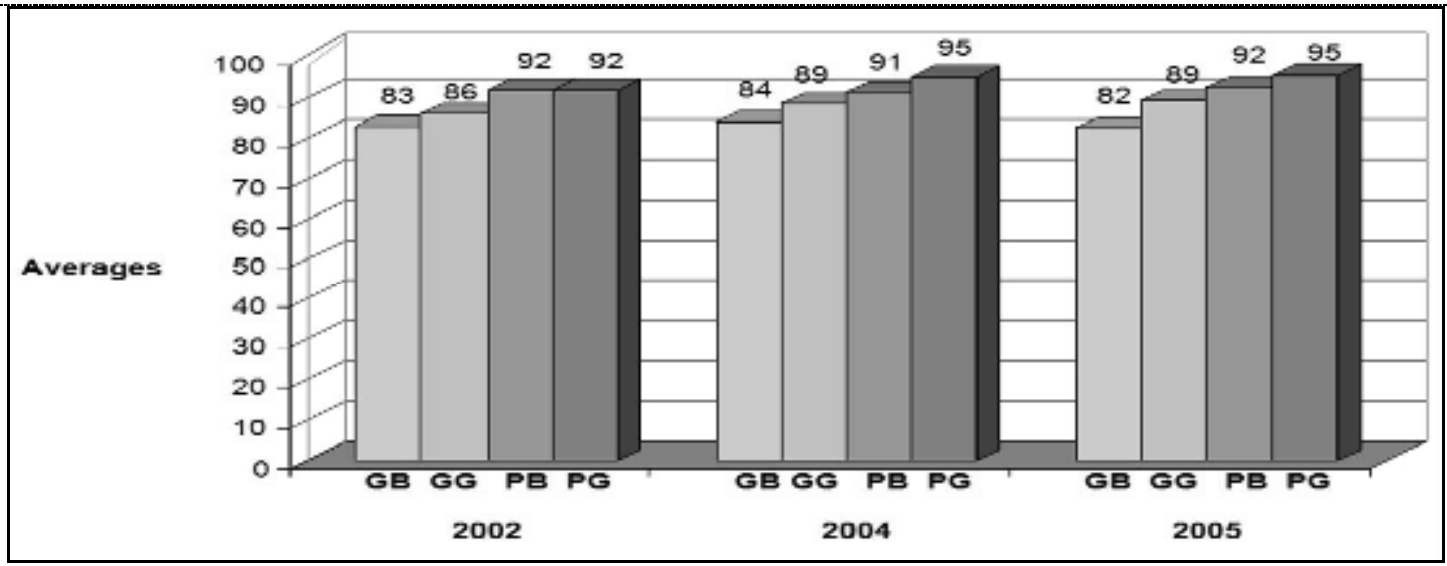

Figure 5. Students' averages before and after the introduction of English.

The chart of the students' averages before and after the introduction of English reveals that there are no indications of any change in their achievement in Arabic-language subjects after they learn English (English was introduced in 2005). However, there is a very slight drop (2\%) in the government school boys' average in 2005 (after English), as they achieved $82 \%$ compared to $84 \%$ in 2004 . The averages of the same group in both 2004 and 2005 are not far from their average in 2002 (83\%). The government school girls achieved the same average of 89\% in both 2004 and 2005 (before and after English). Furthermore, their achievement is slightly better than in 2002 (86\%). On the other hand, the private school students show the same stable averages in 2004 and 2005 as well as in 2002. In the private schools, students had studied English in all three years (2002, 2004, and 2005). However, the comparison of their averages with the averages of the government school students before and after the introduction of English indicates that there was no significant difference. The chart shows that all of the students in both school types have the same averages in 2003 and 2004 (when government school students did not learn English) and 2005 (when all of the students in the sample studied English). In conclusion, the introduction of English in 2005 did not affect government students' achievement in Arabic.

The main hypothesis of this study was that there is no impact of learning English in primary school on students' achievement in Arabic. To examine this hypothesis, the study attempted to answer four research questions. The first question was the most direct one, asking whether or not there is any impact. According to the above information regarding the averages of the students during the three stages of analysis, there is no impact of learning English at the primary level on students' achievement in Arabic subjects. This is a clear answer to the first question of the study, which will be discussed in detail in the next section. The other three questions of the paper were presented to offer deeper information only in the case that any type of impact was reported.

\section{Discussion of the results}

As mentioned previously, the analysis of the students' averages in Arabic subjects did not show any sort of impact from learning English at that stage. There are many studies in the literature review section that report similar findings to this study (Smith, 1967; cf. Burstall, 1970; Burstall, Jamieson, Cohen, \& Hargeaves, 1974; Swain, 1974; Noh, 2001; Bregy, Brohy, \& Fuchs, 2000; Eassa \& Al-Mutawa, 1998; Bjorklund, 1995; Rodriguez, Diaz, Duran, \& Espinos, 1995; Grandell, 1993, 1995; West, 1993, Cummins, 1978; Hoglund, 1992). However, most of those studies were carried out in different contexts and under different circumstances. This study therefore finds a similar pattern of results for students in other contexts, at least among the schools forming the sample for this study.

The main finding of this study is that there is no indication of impact on achievement in Arabic subjects from learning English at the primary level in government schools in Saudi Arabia. However, before discussing the results, possible reasons that might have led to this finding should be noted. Aside from the impact of the foreign language, there are some other external factors that might lead to these findings. Al-Thaferi (1999) stated that the type of impact is not necessarily related to the foreign language itself, as the educational environment could play an important role in determining the level of impact. Other external factors are reported in the literature review.

In the case of this study, the nature of learning English in Saudi Arabian schools is not considered in some respects to be a foreign language-learning program in regard to teaching method, the curriculum, and the amount of teaching hours. English in Saudi schools is taught in regular school classes of 45 minutes four times per week in classes full of Arabicspeaking students and presented by Arabic-speaking teachers. Moreover, the English language curriculum is based on traditional language-teaching methods such as grammar translation and audio-lingual methods that do not give the learners the chance to practice using the language itself. In contrast to the few hours spent teaching English, Arabic is taught in an intensive way with a variety of school subjects such as reading, grammar, writing, dictation, composition, and Arabic literature, in addition to religious subjects such as the Nobel Quran scripts and the prophet's sayings (PBUH), all of which are written in pure, classical Arabic and taught through reading and interpreting their meaning. Furthermore, Arabic is the teaching language of all other school subjects, which makes it the dominant language. All of the above factors create what Krashen (1985) called "a poor acquisition environment." This situation might prevent any alleged negative impact of learning English on the Arabic language that some people in Saudi Arabia fear. 
Moreover, some studies that showed no impact of learning additional languages on the first language have been conducted in foreign or second language environments. This might give some indication that if the first languages of young children who study in immersion programs or learn other languages in their environments have not been affected, then the first languages of young children who study other languages in a formal school environment should not be affected either.

\subsection{The positive and negative impact of learning foreign languages}

The analysis of the students' averages in the study sample shows that there is no indication of a negative impact from learning English on the students' achievements in Arabic subjects (grammar, reading, and writing). However, some studies conducted in Arabic countries that investigated the impact of English on Arabic for primary school students did find some impact. The Qatari study (cited in Al-Mutawa, 1996) reviewed in the literature review section found that those students who had not studied English until their last year of primary school were better in their Arabic comprehensive and speaking skills than students who had studied English beginning in their first year of primary school. However, although the students in this study learned English more intensively compared to students in Saudi government schools, the impact did not last for a long time, and their Arabic comprehension and speaking skills improved in the last year of primary school. In fact, they recorded the same achievement level in comparison to the other students who had not studied English.

Ashor (cited in Al-Mutawa, 1996) has also noted this finding of making up the negative impact after a period of time. In a study conducted in Egypt for Arabic speakers learning English, Ashor found that student achievement in the Arabic language slowed down after they started learning English; however, he noted that this impact disappeared in later years. Even in immersion programs where the foreign language is considered dominant in the school context, the impact does not last for long. Regarding performance in their first language, Noh (2001) argued that there should not be any longterm difference between students of immersion programs and their counterparts who study in the regular school system.

As is clear from the findings of the above studies, the negative impact is temporary and should not be considered a threatening factor. It can be also argued that this impact might be attributed to factors other than the structure of the English language itself. Young learners may give English language learning more interest when they first begin to study it and focus on learning it more than their first language, which may lead to the temporary impact that is usually made up after a period of time when the students get used to the new subject. This increasing interest has been reported by Alma'amori et al. (1983) (cited in Al-Mutawa, 1996), who have referred to the negative impact that they found in their studies as being related to this subject novelty. If we take this argument into account, the findings of those studies are not far from the findings of the current study, that is, nil impact.

On the other hand, learning other languages at this age has some positive effects on students' performance in their first language. Some studies in the literature review support this idea. The best positive effect that students can get from learning other languages is that they know and understand their first language better. Goethe (cited in Vygotsky, 1962) said "he who knows no foreign language does not truly know his own."

In addition, learning other languages can help young learners to develop better metalinguistic awareness that should be reflected in their proficiency of the first language and in learning other languages in general. Teaching other languages to young children, such as English in Saudi schools, should be considered as a way of developing children's cognitive systems and metalinguistic awareness, both of which help in the acquisition of their first language and in foreign language learning (Clyne, 1986; Bamford \& Mizokawa, 1991, cited in Noh, 2001).

Although the findings of the current study did not show an impact of learning other languages on the first language, the cognitive benefits might have been shown to accrue if they had been measured. A study in a similar context to the current one supports this idea. In Egypt, Hinna (1967) noted that although there was no impact on the students' achievement in Arabic, the students seemed to show more progress in their first language acquisition after learning English. Kecskes and Papp (2000) suggested that even learning a foreign language in regular classrooms, as occurs in Saudi schools, could enhance the process of first language development.

Regarding the positive impact on student achievement in their first language, although the analysis of the students' averages in Arabic subjects showed that there was no negative impact of learning English on the students' achievement in Arabic, the charts showed that private school students who had been learning English since year 1 showed better averages and more stable progression patterns in Arabic. However, this improvement was slight, and this data indicates correlations that cannot be clearly and unambiguously attributed to the introduction of English, as other factors may be involved.

\section{Conclusion}

The findings of this study support its main hypothesis. There was no notable impact of learning English on students' achievement in Arabic subjects in Saudi government schools that coincided with the introduction of English. Although some of the data indicated that students of the two private schools who had been learning English from year 1 showed a slightly better performance in Arabic subjects, none of the three levels of the analysis indicated changes that were clearly related to the study of English. The main finding that can be asserted from this study is that analysing the results of the private school students (who study English from year 1) in eight different years showed that they did not have worse results in Arabic than their counterparts in the government schools who were not exposed to learning English. 
This study contributes to the debate about teaching foreign languages in primary schools in Saudi Arabia. Arguments about the impact of learning other languages on children's performance in Arabic might reflect much bigger debates in Saudi Arabia. These debates relate to how Saudi society and culture should respond to foreign ideas and influences. As mentioned previously in the introduction, many of the articles that were for or against teaching foreign languages in Saudi primary government schools were not based on empirical studies. Both sides of the debate use English as an example that represents the type of culture that they want or that they are against. Furthermore, many people suspect that investors in commercial language schools might have played a role in the current campaign for the necessity of learning English at the primary level and its importance for future jobs (Al-Naser, 1991; Husain, 2002). The findings of this study and any other studies in the same field are not expected to stop the argument, although they do add empirical data that may inform the debate.

\subsection{Future studies}

The data in this study involved aggregate scores based on a situation in which English is taught in a way that falls short of meeting optimum conditions for learning. Studies to explore other contexts and more details of Arabic language development would add to the empirical data, further informing debates in Saudi Arabia about the desirability of introducing English language learning into the primary school curriculum.

\section{References}

Al-Ahmari, M. (1992). From speaking other languages to losing the identity. Al-Bayan Magazine, 54, $109-110$.

Al-Ghanim, F. A. (2000). Before we start. Al-Marefah Magazine, 57, 77.

Al-Jarf, R. S. (2004). Should we teach English to children under the age of six? Paper presented at early childhood: Characteristics and needs. Riyadh, Saudi Arabia.

Al-Maqoshi, A. (2008, April 29). Between scarcity and glut in the labor market. Alriyadh Newspaper.

Al-Mutawa, N. (1996). Attitudes of Kuwait society towards introducing English as a foreign language at primary schools (EFLPS). The ERC Journal, University of Qatar, 9(5), 7-37.

Al-Naser, M. (1991). Teaching foreign languages to children. Al-Bayan Magazine, 36, 71-73.

Al-Shammary, E. A. (1989). Teaching English in Saudi Arabia: To whom, when and how should English be taught? The Journal of King Saud University, 1(2), 195-222.

Al-Thaferi, M. (1999, January 26). The impact of the introduction of English subject on Arabic language in the elementary level in Kuwait schools. Al-Watan Newspaper.

Bregy, A. -L., Brohy, C., \& Fuchs, G. (2000). Experience d'apprentissage bilingue precoce: Resultats des eleves de Monthey et de Sion a la fin de la 2e Anee Primaire, Annee 1998/99 [Experience of preschool bilingual education: Results from students in Monthey and Sion at the end of second grade, 1998/99 year].

Clyne, M. (Ed.) (1986). An early start: Language at primary school. Melbourne: River Seine Publications.

Cummins, J. (1978). The cognitive development of children in immersion programs. Canadian Modern Language Review, 34(5), 855-883.

Eassa, M. R., \& Al-Mutawa, N. A. (1998). Introducing EFL at primary school and its effect on Arabic. The Educational Journal, 12(46), 115-146.

Hinna, F. F. (1967). The impact of learning foreign language on learning the national Arabic language (Unpublished master's thesis). Faculty of Education, Ayn Shams University, Egypt.

Husain, M. (2002). Our children and the foreign languages schools. Al-Bayan Magazine, 122, 45-51.

Jazaeri, M. (2003, May 5). The debate of teaching English in elementary level is back. Asharq Alawsat Newspaper. Retrieved from http:/www.aawsat.com/print.asp?did=168985\&issueno=8924

Johnson, J. S., \& Newport, E. L. (1989). Critical period effects in second language learning:

The influence of maturational state on the acquisition of English as a second language. Cognitive Psychology, 21(1), 60-99.

Kecskes, I., \& Papp, T. (2000). Foreign language and mother tongue. Mahwah: Lawrence Erlbaum Associates.

Krashen, S. D. (1985). The input hypothesis. London: Longman.

Lenneberg, E. (1967). Biological foundations of language. New York: Wiley.

Long, M. (1990). Maturational constraints on language development. Studies in Second Language Acquisition, 12, 25185.

Masciantonio, R. (1977). Tangible benefits of the study of Latin: A review of research. Foreign Language Annals, 10, 375-382.

Meara, P. (1983). “Introduction.” In P. Meara (Ed.), Vocabulary in a second language (pp. ii-iv). London: CILTR.

Noh, K. H. (2001). An English immersion program in a primary school in Korea. Melbourne: La Trobe University.

Patkowksy, M. (1980). The sensitive period for the acquisition of syntax in a second language. Language Learning, 30, 449-472.

Penfield, W., \& Roberts, L. (1959). Speech and brain mechanism. London: Oxford University Press.

Rodriguez, J. L., Diaz, R. M., Duran, D., \& Espinosa, L. (1995). The impact of bilingual preschool education on the language development of Spanish-speaking children. Early Childhood Research Quarterly, 10(4), 475-490.

Swain, M. (1974). French immersion programs across Canada: Research findings. Canadian Modern Language Review, 31(2), 117-129.

Vygotsky, L. S. (1962). Thoughts and language. Cambridge, MA: MIT Press. 